\title{
Los libros de coro y las principales causas extrínsecas de su deterioro
}

\author{
Javier Bueno Vargas, Elena Vázquez Jiménez
}

Resumen: Con unas características muy particulares, los libros corales están formados por una serie de materiales que conviven en una tipología de libros condicionada por su gran formato y peso. La interrelación y variedad de los elementos empleados, sus características morfológicas y una serie de causas extrínsecas e intrínsecas de degradación, se manifiestan reiteradamente en estos volúmenes. La falta de investigaciones en profundidad, especialmente de los libros de coro españoles, nos ha llevado a abordar el proyecto de estudiarlos, conocerlos y difundir el conocimiento generado para su reconocimiento y puesta en valor como bien cultural en peligro.

Palabras clave: Conservación; Preservación; Libros de coro; Deterioro; Mobiliario.

\section{Os livros de coro e as principais causas extrínsecas da sua degradação}

Resumo: Com características muito particulares, os livros corais são formados por uma série de materiais que integram uma tipologia de livros que condiciona o seu grande formato e peso. A interacção e variedade dos elementos aplicados, a sua morfologia e o número de causas extrínsecas e intrínsecas de degradação manifestam-se repetidamente nestes volumes. A falta de investigações aprofundadas, especialmente sobre livros de coro espanhóis, levou à criação deste projeto para estudá-los, conhece-los e difundir o conhecimento gerado, para o seu reconhecimento e valorização como património cultural em perigo.

Palabras-clave: Conservação; Preservação; Livros de Coro; Deterioração; Mobiliário.

\section{The choral books and the main extrinsic causes of their degradation}

\begin{abstract}
With very particular characteristics, choral books consist of a series of materials that coexist in a typology of books influenced by its large format and weight. The interplay and variety of the elements used, their morphological characteristics and a number of extrinsic and intrinsic causes of degradation, occur repeatedly in these volumes. The lack of research and in depth, especially the Spanish choir books, has led us to address the draft study, knowledge and disseminate the knowledge generated for recognition and value as cultural heritage in danger.
\end{abstract}

Keywords: Conservation; Preservation; Choir books; Deterioration; Furniture.

\section{Introducción}

Los libros de coro, también conocidos como cantorales, libros corales o libros de canto gregoriano son obras de gran formato: pueden llegar a medir el metro de altura, sobrepasar los cuarenta kilos y debían ser elaborados con materiales resistentes para poder soportar el trasiego diario. Aunque presentan una gran diversidad de materiales y diseños, responden a unas características comunes; un cuerpo normalmente realizado en pergamino (aunque existen también ejemplares en papel 
normalmente libros de polifonía o de factura más reciente), una estructura ligatoria resuelta mediante el empleo de nervios simples o dobles (para los que se utilizaba badana enrollada, cuerda o tiras de cuero) y cabezadas sencillas (hechas con hilo de lino o cáñamo y generalmente poco decoradas). Sus tapas están conformadas por distintas piezas de madera ensambladas y revestidas habitualmente con piel curtida; encontramos además varios elementos metálicos de refuerzo (bullones o bollones, cantoneras, bandas perimetrales y cierres). Para poder sacarlos de las estanterías o librerías pueden tener en sus lomos tiras de cuero (utilizadas en muchos ejemplares del Sacromonte de Granada), cuerdas (empleadas en algunos de los libros corales de la catedral de Jaén) o incluso ruedas en los cantos inferiores (existen algunos ejemplos en los volúmenes del monasterio de Guadalupe extremeño). El contenido de su interior es la música expresada a través del canto llano o gregoriano, con textos en latín y ricas iluminaciones, que ayudaban a indicar el comienzo de cada rezo (Bueno, Espejo y López 2005).

Pese al papel imprescindible que jugaron estos libros en un período histórico amplio, su historia material ha tenido serias consecuencias directas: la merma de colecciones, del número de ejemplares e incluso la pérdida de parte de los contenidos de muchos volúmenes. Este patrimonio reclama nuestra atención y una urgente puesta en valor ya que se encuentra aún pendiente de cuantificar, a pesar de su riqueza tanto material como de sus contenidos musicales y decorativos. Por ello con este artículo queremos mostrar las situaciones habituales adversas en las que se suelen encontrar las colecciones corales en España y aprovechar para difundir las diferentes líneas de investigación iniciadas para su adecuada ubicación patrimonial como bienes culturales; estas líneas son: el análisis de colecciones, la cuantificación de ejemplares, el estudio de los espacios y medioambiente en los que se sitúan, el conocimiento de sus materiales y técnicas constituyentes, su conservación, restauración y la puesta en valor de estos libros. Nuestra especialización en el ámbito de la conser-

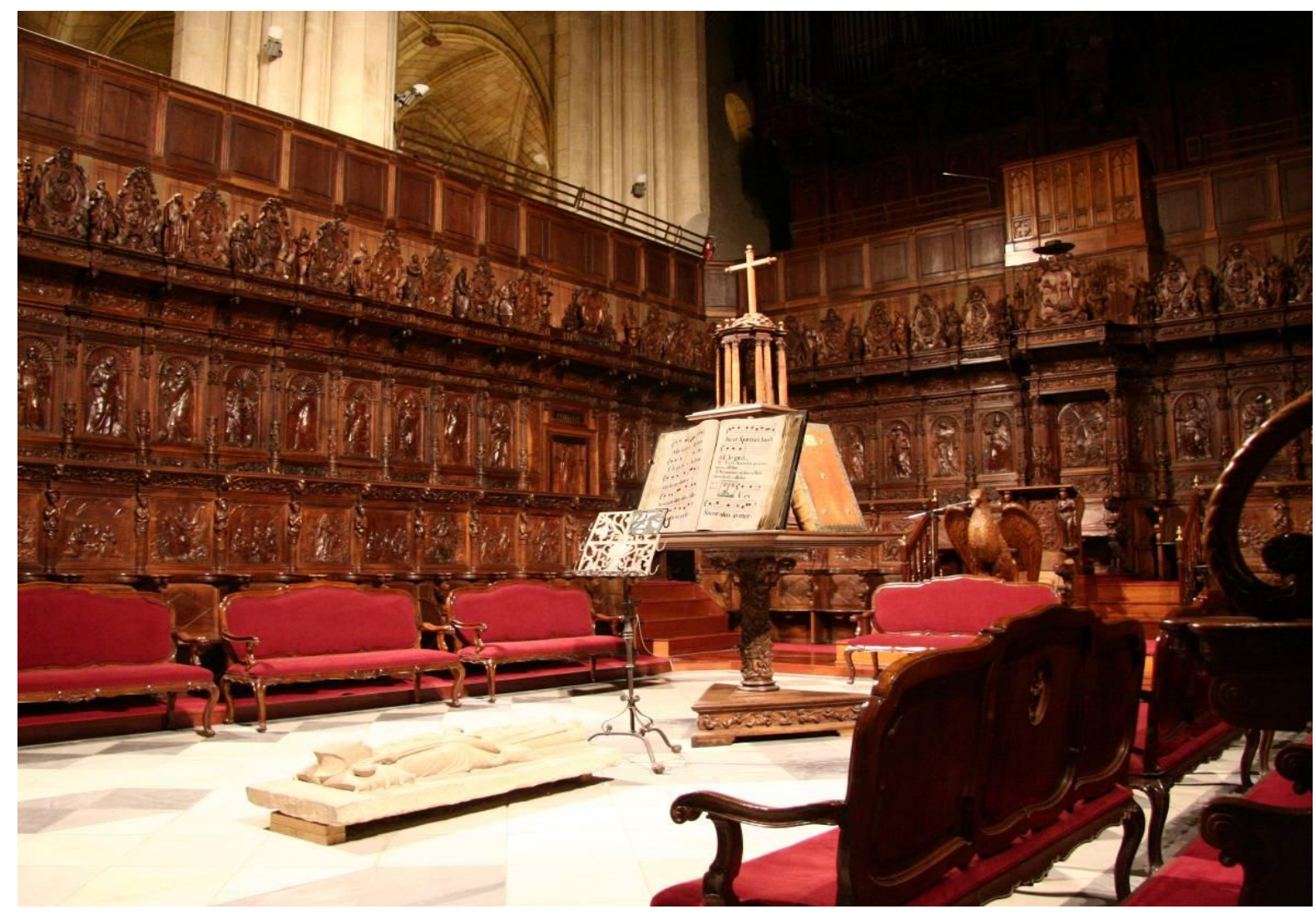

Figura 1. Libros inadecuadamente expuestos en el facistol de la catedral de Murcia. 
vación y restauración está haciendo que se dedique especial énfasis al estudio de las técnicas de creación y a los procesos requeridos para su conservación o restauración, así como al desarrollo de su registro en bases de datos específicas que recojan además características históricas, codicológicas y musicológicas desarrolladas por expertos en estas materias.

Han sido muchos los cambios acaecidos en el micromundo del canto litúrgico coral a lo largo de la Historia y especialmente desde mediados del siglo pasado en España. De ser protagonista indiscutible de ceremonias diarias desarrolladas en innumerables recintos conventuales, iglesias o catedrales, los libros de coro se han convertido en elementos patrimoniales en total desuso, salvo puntualmente el decorativo, presentando un generalizado abandono. Si bien se han producido algunos intentos de recuperar el canto llano o gregoriano que contienen, esta situación de desinterés por los libros creados en distintos estilos y épocas, e incluso en muchos casos el desconocimiento de su existencia, ha originado que en la mayoría de las situaciones los recintos que aún los albergan carezcan de un lugar y condiciones adecuados, al menos, para su correcta conservación.

\section{Contextualización, ubicación física y uso habitual}

Entre las distintas patologías que inciden en el actual estado de conservación de los cantorales han sido de suma importancia dos aspectos: el lugar de uso y el de almacenamiento; frente a la unidad de planteamientos en relación a su uso habitual en los coros [Figura 1], aunque actualmente como meros objetos decorativos, nos encontramos una gran diversidad en cuanto a las propuestas que se han ido tomando para su almacenaje.

Cada institución ha elegido distintas medidas de almacenamiento en las colecciones examinadas hasta el momento: el monasterio de Yuso en San Millán de la Cogolla (La Rioja), el real monasterio de Guadalupe (Extremadura), la catedral de Pamplona, el colegio seminario del Corpus Christi (Valencia), la iglesia prioral de Santa María de la Asunción en Carmona (Sevilla), la abadía del Sacromonte y la Capilla Real (Granada), la catedral de la Asunción de la Virgen (Jaén), el museo-palacio de Viana (Córdoba), la iglesia de Nuestra Señora de la Encarnación en Vélez-Rubio (Almería) y la catedral de México D.F. La incorporación de la música en el rito católico favoreció la aparición de los coros, que fueron conformando tanto un espacio propio, con unas características determinadas en cada edificio, como los elementos y mobiliario que en él se utilizaban. Destacaban dos elementos: la sillería del coro y el facistol que, junto a otros elementos imprescindibles como las rejas o las barandillas, los sotocoros y frentes de coro más o menos decorados (Fernández-Shaw 1994), compartían espacio con otros elementos auxiliares: los atriles, las taquillas para los libros del punto (en donde se anotaban las asistencias, faltas o retrasos en el coro), los carritos para llevar los libros, o los bancos y las mesas auxiliares; la incorporación de los órganos sería otro tema a destacar.

\section{Los coros y las sillerías}

Arquitectónicamente los coros como recintos específicos y separados en el interior de las edificaciones han tenido diversas ubicaciones, pudiéndose situar bien en el presbiterio, en la nave central o bien a los pies de la iglesia, sobre la entrada principal. También se pueden situar a dos niveles: a pie de calle o en una zona alta generalmente sobre la entrada; suelen estar separados del resto del recinto por puertas o rejas, para salvaguardar tanto a los cantores como a los bienes que custodiaban.

El principal mobiliario que contienen los coros son las sillerías. Conocemos de su importancia por los contratos que se conservan en numerosas instituciones en donde se fijaban las premisas como el diseño o los materiales a utilizar. Estas creaciones lignarias fueron realizadas en maderas resis- 
tentes existiendo predilección por la caoba y alternándose con otras especies como el pino de Flandes, el granadillo, el cedro, el ébano, el castaño o el roble entre otras (Martín 2004: 41). Generalmente quedaban en blanco (sin policromías). Los encargados de elaborar estos muebles eran los "carpinteros", también jerarquizados en oficiales y obreros. En esta corporación estaban involucrados escultores, imagineros, ensambladores, entalladores, torneros, carpinteros y fusteros. Con el matiz religioso como diferencia principal entre el escultor y el imaginero, ambos realizaban obras de bulto redondo, quedaba para los entalladores la labor de realizar los relieves. De forma similar también se diferenciaban el tornero y el fustero (este último, especializado en el cuerpo principal de las columnas). Finalmente participaban los ensambladores, que además de confeccionar piezas, unían el trabajo; eran ayudados en el ajuste a la arquitectura por los architeros, oficio distinto al del arquitecto, pero que hacían obras menudas o de menor importancia.

Por otro lado y con una estructura mayoritariamente en forma de herradura, habitualmente cerrada por una reja o barandilla, las sillerías suelen estar organizadas en dos o tres niveles. En su distribución podemos observar claramente reflejada la rígida jerarquía que establecía la Consueta o Libro de Ceremonias, que junto con el Libro de reglas y normas, los Libros de Cabildo o los Libros de Cuentas, se convierten en fuentes fundamentales de información sobre estos temas. En general el nivel superior estaba reservado para los altos cargos siendo la zona central ocupada por la presidencia (Prelado, Abad o Abadesa), siendo los asientos contiguos para los caperos en las abadías. En el nivel inferior o coro bajo se sentaban prebendados, capellanes o capitulares y se destinaba el centro al sitial, es decir, era el lugar ocupado por otros miembros principales en la jerarquía de la institución, por ejemplo en la catedral de Pamplona eran tres: el Preste y los Ministros y junto a ellos estaban el diácono y el subdiácono (Biurrun 1935: 288). En instituciones dedicadas a la formación se situaban en este nivel, o incluso en otro inferior, los colegiales, que solían ocupar bancos corridos y sin respaldo.

Respecto a su estado de conservación hay que destacar dos factores: por un lado, los materiales constituyentes y por otro, la evolución histórica. Se trata de un mobiliario realizado con maderas y trabajos de gran calidad y durante el período en que se utilizaron habitualmente pudieron sufrir deterioros puntuales propios del uso, como el desencolado y/o pérdida de pequeñas piezas, roces y astillamientos o decoloraciones; pero no son habituales los daños por mala factura (como pudieran ser alabeos, exudaciones de resina o debilidad estructural). Los daños se han intensificado especialmente por el abandono o escaso mantenimiento, que ha favorecido la acumulación de polvo, desarrollo de ataque biológico (insectos, mamíferos, microorganismos, etc.). No obstante, la estabilidad microclimática de las instituciones que los albergan ha favorecido que se maticen mucho los deterioros por condiciones ambientales adversas, salvo los provocados por catástrofes naturales o intencionadas. Al igual que los libros corales, el deterioro de este mobiliario se intensificó por factores históricos, como revueltas políticas y guerras, destacando en España la Guerra de la Independencia Francesa (1808), la Desamortización de Mendizábal (1836) y la Guerra Civil (19361939). En estos períodos las instituciones religiosas se desacralizaron y se convirtieron en cuarteles, hospitales o cuadras para animales y muchos coros fueron incendiados, como especialmente en el caso de la provincia de Sevilla (Martín 2004: 19). Por otro lado, la evolución de los estilos musicales eclesiásticos, artísticos y del gusto así como las reformas realizadas en los edificios que los albergaban y las introducidas en el propio culto, modificaron sus estructuras y acabados, determinando en el tiempo su grado de deterioro. El desinterés demostrado por estas piezas ha favorecido que se adapten para otros usos mobiliarios (desmembrándose en distintas estancias o convirtiéndose, por ejemplo, en puertas de armario en las sacristías), o que se trasladen dentro del mismo edificio. Martín Pradas (Martín 2004: 22) recoge, por ejemplo, que en Sevilla algunas Hermandades de Penitencia con sede en exparroquias los movieron para poder colocar sus pasos procesionales. Otros se vendieron de unas parroquias a otras, o se desmembraron y vendieron a anticuarios; en resumen, 
este mobiliario ha seguido un progresivo camino hacia su desaparición, al igual que los libros de coro.

No obstante, a principios del siglo pasado habían sobrevivido numerosas sillerías, como las 165 que estudió Pelayo Quintero Atauri en 1908, estudio que publicó con el nombre de Sillerías de coro en las Iglesias Españolas y que fue editado por la Real Academia Hispano-Americana de Ciencias y Artes. Escaso inventario éste, porque Martín Pradas recoge en su estudio Las sillería de coro de SeviIla (Martín 2004) nada menos que 70 conjuntos corales sólo en la ciudad de Sevilla. Podemos hacer un seguimiento de este mobiliario en otros estudios como los de Isabel Mateo Gómez de 1979 sobre las sillerías góticas, los de Leopoldo Torres Balbás de 1981 sobre las de estilo mudéjar, los de Benito Navarrete Prieto sobre los coros barrocos, o el de Pedro Navascués Palacios de 1998 sobre el desmantelamiento de las sillerías corales de varias catedrales españolas.

\section{Los facistoles y los atriles}

Especialmente para que el canto pudiera ser homogéneo se hacía recomendable el compartir el mismo texto musical; esto derivó hacia la fabricación de los grandes libros que conocemos como cantorales que, colocados en el centro sobre un atril de gran tamaño, el facistol [Figura 2], podían ser seguidos por el coro. Podía haber dos ${ }^{1}$ o incluso más en cada institución como vemos recogido en el Libro de Cabildos no 11 de la abadía del Sacromonte de Granada, p.325v de 3 abril de 1777: ...en medio de la Yglesia havía necesidad de un facistol nuevo, y también otro fixo en el coro.

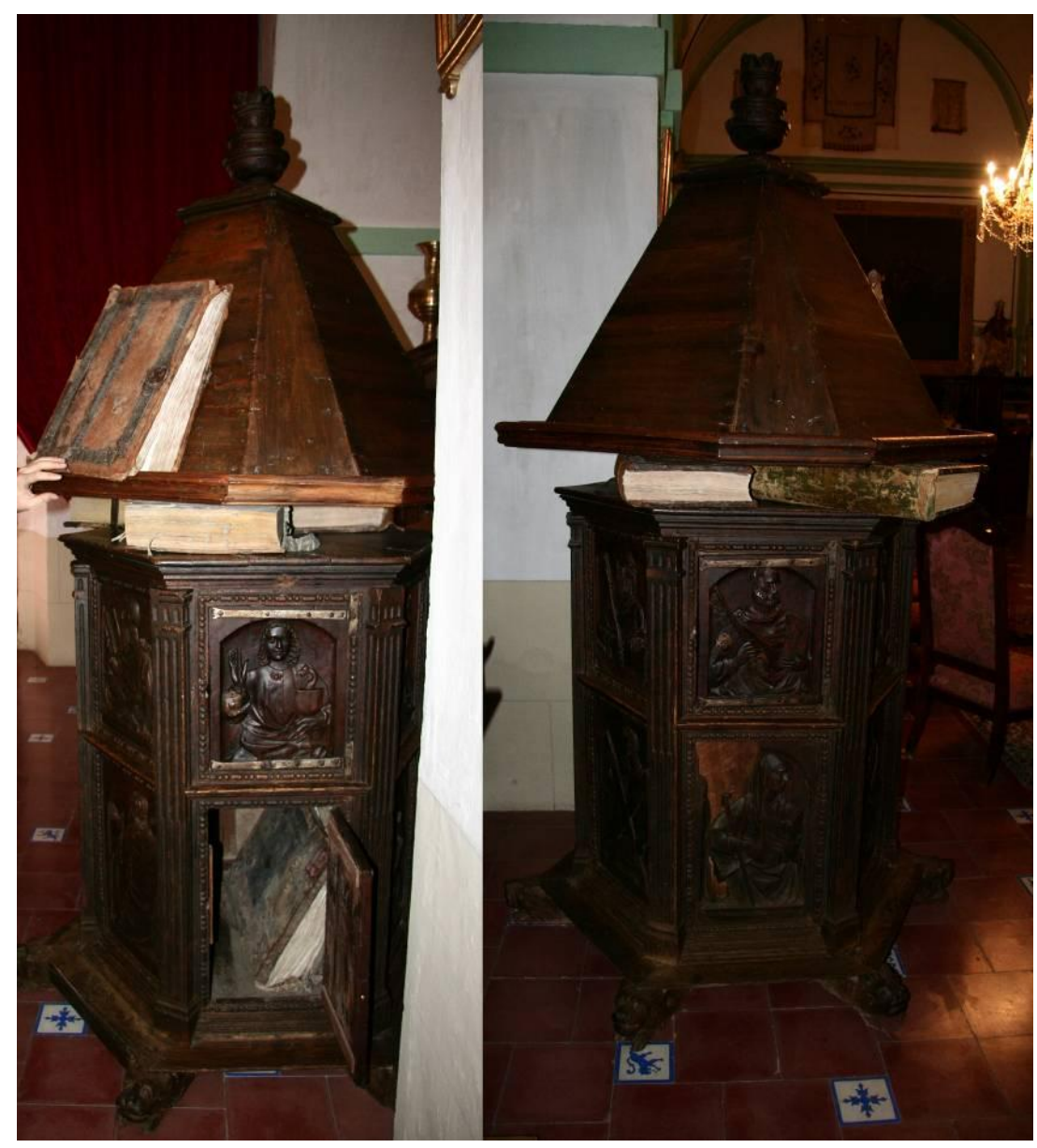

Figura 2. Facistol de la iglesia de la Encarnación de Vélez Rubio, Almería, con un libro en el interior del pie, otro expuesto y otros almacenados bajo la base giratoria. 
Elaborados en madera o metal y con una decoración más o menos profusa, conforme a distintas épocas y estilos, los facistoles constan de distintas partes: una baja o basamento fijada al suelo que podía incluir una zona de almacenaje con puerta en donde se podían guardar los cantorales empleados, una zona media móvil mediante un eje vertical (en ocasiones con un sistema de bloqueo) y con cuatro caras inclinadas para apoyar los libros y el remate, a veces con esculturas.

Cuando el diseño de éstos no presentaba la posibilidad de almacenamiento, en ocasiones se recurría a un mueble auxiliar ${ }^{2}$ o se buscaban otras soluciones para colocar estos robustos libros durante el canto: Ante la sillería, un alargado pupitre sirve para colocar los pesados libros de coro. Cada libro sirve para dos monjes. El centro del coro lo preside, solemne, solitario, el facistol. En él se proclaman las lecturas y a veces el rezo de las preces. (Rosendo 2007). Otros elementos que servían de apoyo a libros más pequeños son los atriles móviles de madera o metal, con pies o que se podían fijar a lo largo de las barandillas.

El responsable de seleccionar o registrar los libros de coro era el sochantre y para el traslado hasta el facistol se contaba con los versicularios o con alumnos, en aquellas instituciones que también tenían formación. El arrastre de los pesados libros, las caídas o la dificultad de colocar los corales en el facistol han contribuido al acelerado deterioro de ambas piezas, tanto de los revestimientos, decoraciones y estabilidad de las encuadernaciones, como del propio mueble. Sobre el poco interés por la conservación de estos elementos, se han encontrado algunas referencias; así el Libro de Cabildos de la abadía del Sacromonte de Granada n 5. p. 267r, de 11 junio de 1686 recoge que: se determinó se hiciera un facistol nuevo y capaz de los libros por quanto es mui pequeño y esta mui viejo el que ay y se caen y echan a perder los libros; el Libro de Cabildos n6 p.114r recoge otra noticia del 1 de septiembre de 1698 al respecto: Item se determino que porque el facistol del coro está muy maltratado (...). Se puede hazer uno nuevo aprovechando del Viejo lo que pudiere servir.

El trayecto a recorrer por los libros corales desde el archivo al facistol se convertía en una fuente habitual de deterioro de ambos, sobre todo cuanto más lejos estaba el archivo o librería de cantorales del coro.

\section{Causas extrínsecas de deterioro}

\section{Los libros de coro y los factores medioambientales}

Los cantorales, además de por una serie de causas de degradación intrínsecas (Bueno 2006) y propias de los materiales empleados, se veían alterados por causas extrínsecas. Junto a los efectos propios de la manipulación humana, la influencia de las condiciones ambientales son las causas principales de una buena o mala conservación de los bienes culturales. La mejor manera de preservar los bienes culturales consiste en mantenerlos en "condiciones constantes de temperatura y humedad con un grado de pureza atmosférica" (UNESCO 1979: 35).

En base a lo anterior, podemos decir que si nos preocupa conocer la incidencia del medioambiente en un libro de coro, los parámetros principales que se deberían tener en cuenta son la temperatura y la humedad relativa (HR). Menos determinantes pueden ser otros parámetros (contaminación, iluminación, latitud, altitud, topografía y composición de los suelos próximos, corrientes de aire o contenido en sales entre otros), porque no suelen afectar significativamente a estos libros especialmente por el poco uso que de estas obras se hace desde hace mucho tiempo. Recordemos que son libros que han podido estar incluso durante siglos almacenados sin abrirse y en la mayoría de los casos dejaron de emplearse en España de forma habitual especialmente a lo largo del siglo 
XX, confirmándose su desaparición de la liturgia con el cambio promovido en ésta por el Concilio Vaticano Il y al celebrarse las misas en lenguas vernáculas en reemplazo del latín.

Aunque el clima puede sufrir oscilaciones diarias, estacionales y anuales considerables, la ubicación de archivos de libros corales en edificios históricos (iglesias, catedrales, monasterios, ayuntamientos, palacios o casas señoriales) se convierte en un factor positivo. Estos edificios generalmente de gruesos muros, suelen matizar las oscilaciones externas estacionales y diarias, hasta parámetros más adecuados para la conservación de estos artefactos culturales: temperatura en torno a $18^{\circ}-20^{\circ} \mathrm{C}$ y humedad relativa en torno al $40-60 \%$.

Estos factores afectan a los libros corales de una forma muy importante, al estar constituidos mayoritariamente por materiales orgánicos como los soportes proteínicos, (cueros y pergaminos) y celulósicos (papel), los adhesivos de origen animal o vegetal, los textiles, las maderas o la cordelería (en cabezadas, nervios e hilos de cosido). También afectan a la conservación de las ilustraciones o miniaturas, cuyas técnicas pictóricas (Bueno 2006; Martínez 2001), pueden verse muy alteradas por unas inadecuadas condiciones.

En este sentido, el medioambiente aglutina a los factores que en primer lugar y de una forma determinante influyen y determinan los cambios estructurales en los bienes patrimoniales (Stolow 1987: 4), además de provocar una importante serie de alteraciones y modificaciones químicas. Los parámetros aceptables de humedad y temperatura para unos materiales (el cuero o el pergamino requieren una atmósfera con un $40-60 \%$ de HR), pueden ser desastrosos para otros (los metales requieren una humedad relativa del $0 \%$ ). Los factores medioambientales además no pueden ser eliminados (como sí podríamos intentar hacer con la contaminación), o reducidos a valores mínimos por norma (lo que podemos hacer, por ejemplo, con el tiempo de exposición a la luz). Además las variaciones y oscilaciones rápidas, como las diarias o las ocurridas en los transportes, son los que más afectan en comparación con las estacionales o anuales.

\section{Interacción de la temperatura en la conservación de los cantorales}

Respecto a la influencia del factor temperatura hay que mencionar que comparativamente, las bajas temperaturas son menos dañinas que las altas, aunque producen cambios dimensionales y la aparición de cuarteados, descamaciones, manchas o rigidez y por tanto, fácil fractura en el caso de las maderas, cueros y pergaminos; cambios y deterioros incentivados si hay fluctuaciones. Las altas temperaturas provocan daños físicos y químicos, llevando a la pérdida de estabilidad y a la deshidratación, daños que se mencionarán también en relación a la baja humedad relativa; si la temperatura es muy alta los daños pueden ser irreversibles y se puede llegar a la destrucción por combustión.

\section{Interacción de la humedad relativa con los libros de coro}

Como la humedad relativa depende directamente de la temperatura, estos dos factores deben estudiarse conjuntamente, además todas las reacciones químicas que se pueden producir por efecto de la humedad relativa se aceleran cuanta más alta sea la temperatura.

Una mayor o menor sequedad o humedad climática provoca una serie de reacciones que tienen su origen a partir de un proceso de absorción o desprendimiento de humedad (en pergaminos, papeles, cueros, textiles o maderas). Estas obras son capaces de amortiguar hasta cierto punto los efectos y cambios de las fluctuaciones medioambientales gracias a su contenido en humedad; por 
ejemplo con un $50 \%$ de HR ésta es de en torno al $16 \%$ en las pieles, $12 \%$ en la madera, $7,5 \%$ en la cola animal y 5\% en el papel (Raphael 1993).

La pérdida de la higroscopicidad y la disminución del tamaño debidas a una alta y continua sequedad, en el caso de los pergaminos y en menor medida en el cuero, se explica si sabemos que las proteínas en su estado natural poseen una determinada conformación espacial, mantenida mediante interacciones no covalentes por enlaces o puentes de hidrógeno; aunque éstos no posean mucha energía, pueden afectar a la estabilidad en los niveles estructurales secundarios, terciarios y cuaternarios de las proteínas (Jimeno 1996: 77-82) . Las moléculas de agua (Blazej 1984) participan en esos enlaces no covalentes al formar una cubierta hidratante alrededor de las cadenas de aminoácidos (que son las que conforman las proteínas), siendo unidas a éstos por enlaces de hidrógeno y contribuyendo a la estabilidad estructural. Pero si la estructura de la proteína pierde muchas moléculas de agua pierde interacciones no covalentes disminuyendo la estabilidad de la estructura, produciéndose su desnaturalización; es decir, cambia su conformación espacial al contraerse y realizarse interacciones irreversibles entre aminoácidos. Esto, provoca que los soportes proteínicos sean incapaces de volver a rehidratarse en muchos de los casos e incluso una gran desecación impide generalmente su completa rehidratación (Erhardt y Mecklenburg 1994). Sin embargo, como la desnaturalización no afecta a los enlaces peptídicos que existían entre los aminoácidos, al volver a las condiciones normales, algunas proteínas pueden, en ciertas ocasiones, recuperar su conformación primitiva; es lo que se denomina renaturalización (Jimeno 1996: 83).

En el pergamino, la humedad relativa inferior al $40 \%$ ya es perjudicial; en el cuero, si ese valor baja del $25 \%$, se puede crear una "memoria" que hace que desde ese momento tenga tendencia a contraerse irreversiblemente (Silvio 1997: 82).

En general, si la humedad relativa baja del 35\%, aparecen deterioros físicos como deformaciones, dureza, rigidez, debilidad y contracciones disparejas (como se ha comentado al realizarse interacciones entre aminoácidos en el caso de los pergaminos o cueros) y desecación en las maderas. Por el contrario, una humedad relativa alta, de más del $65-70 \%$, afecta provocando un importante aumento de tamaño. En el caso de que sea elevada y continua, el colágeno se descompone y se despolimeriza, convirtiéndose en gelatina y puede unir hojas o transponer tintas o miniaturas a las páginas contiguas, favoreciendo el ataque de microorganismos.

Los cambios cíclicos rápidos hacen que se pierda elasticidad (capacidad de volver a su estado original) y plasticidad (la deformación es permanente), y provocan la circulación de componentes solubles (resinas de maderas, aglutinantes de capas pictóricas, o componentes en cueros, pergaminos y papeles). Algunos pigmentos cambian su composición y color en alteraciones irreversibles y estables: la azurita pasa a malaquita que es verde, el cinabrio (sulfuro de mercurio) que es rojo, pasa a negro (metacinabarita) (Gómez 2002: 83-84). También se puede provocar corrosión de metales (oro y plata falsa empleada en las miniaturas, bronce, chapas de lata o clavos de hierro) y movimiento de sales y eflorescencias por secado o condensación si baja la temperatura.

\section{La luz y la conservación de los cantorales}

Se ha comentado que estos libros suelen estar almacenados o archivados y poco expuestos a la luz, salvo los ejemplares que forman parte de exposiciones o los que fueron iluminados con velas o lámparas de aceite. Si su iluminación es con luz de radiación controlada en cuanto a la emisión de ultravioletas e infrarrojos y no supera las recomendaciones habituales para la exposición de documentos (50 lux), podremos hablar de parámetros aceptables. Estos se consiguen en la actualidad 
con iluminaciones con fibra óptica como la instalada en las vitrinas con cantorales en la nueva musealización del monasterio de Guadalupe (Cáceres) o en la iluminación de piezas de cuero del museo de Cluny (París). El deterioro habitual en el libro de coro ocurre cuando éste se abre por una página (generalmente la de la miniatura más espectacular) y se deja así durante meses, en exposiciones temporales; o años en exposiciones permanentes. En estos casos el daño se podría minimizar si se hiciera una rotación tanto de páginas como de libros exhibidos y se colocaran filtros mediante vitrinas o cajas de protección con cierta ventilación (por ejemplo de metacrilato con perforaciones o no selladas para evitar además condensaciones). Especialmente habría que seguir estas recomendaciones básicas en aquellos cantorales expuestos en los facistoles de los coros que suelen estar iluminados con potentes proyectores (dada la necesidad de iluminar un gran espacio) [Figura 1], o a los que pueda llegar la luz directa desde ventanas o vidrieras.

\section{Daños biológicos de los libros de coro}

Como consecuencia de la escasa ventilación, las elevadas temperaturas y humedad, la oscuridad y la falta de mantenimiento y limpieza [Figura 5], se suelen dar las circunstancias idóneas para la proliferación de alteraciones de tipo biológico. Los roedores e insectos se alimentan de los materiales degradados (sólo se suelen alimentar del pergamino hidrolizado por una alta $\mathrm{HR}$, o de las maderas) y dejan abundantes excrementos y residuos como serrín, detritus, regueros de orín, etc. Las bacterias y hongos destruyen los papeles, el pergamino y el cuero que se descomponen por la acción enzimática al consumir el carbono presente en las moléculas de celulosa y de las proteínas, para obtener nutrientes; además excretan ácidos orgánicos y ciertas sustancias colorantes que debilitan y manchan los materiales degradados y dejan su impronta irreversible sobre las superficies en forma de manchas variables. En el caso de los adhesivos, alteran o se alimentan de las colas orgánicas que pierden su poder adherente o desparecen [Figuras 3 y 4]. Estructuralmente, los nervios, el revestimiento y lomo se pudren por lo que las encuadernaciones se deshacen.

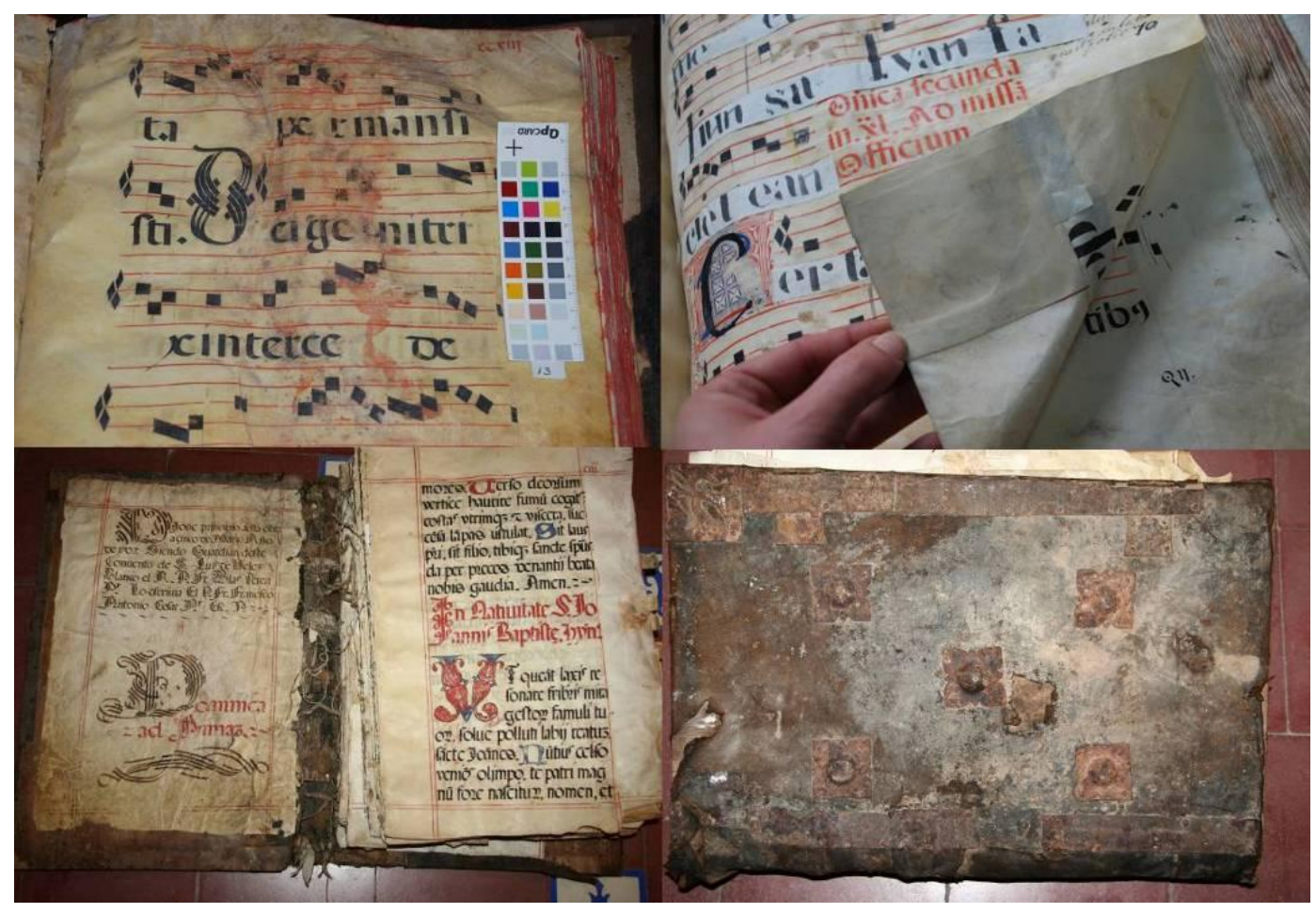

Figura 3. Arriba: a la izquierda, libro de coro del Palacio de Viana en Córdoba y a la derecha, de la iglesia prioral de Carmona en Sevilla. Abajo: libro de la iglesia de la Encarnación de Vélez Rubio abierto y cerrado. 


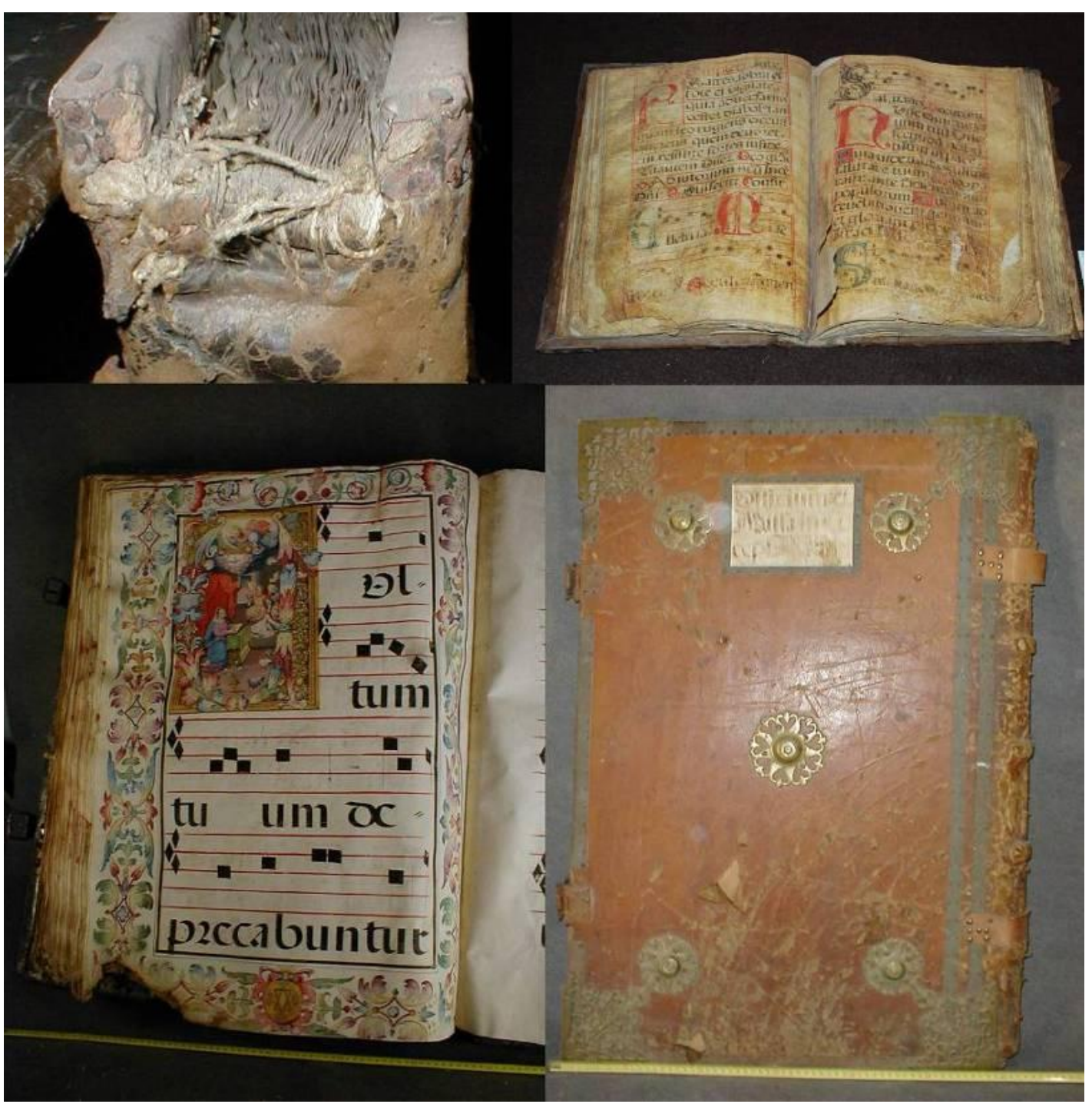

Figura 4. Detalles de libros de coro de la abadía del Sacromonte de Granada y arriba a la derecha, de la iglesia prioral de Carmona en Sevilla.

\section{El uso y mantenimiento de los corales}

Son bastante comunes las alteraciones producidas durante su uso, incluidas reparaciones y recomposiciones [Figura 4]. En muchas ocasiones, elementos como correas en el lomo o cierres han desaparecido y los elementos metálicos como bullones y esquineras que servían para su protección, se encuentran en ocasiones rotos o desaparecidos. Aunque la estructura ligatoria solía estar hecha a conciencia y teniendo en cuenta su peso, el uso hace habitual la presencia de nervios y cabezadas rotos y el desprendimiento de cuadernillos y tapas.

Los principales daños que se suelen encontrar en el interior de los cantorales ya se apuntaron en el artículo: "Deterioro en encuadernaciones manuscritas de gran formato: causas intrínsecas de alteración en los libros de coro" (Bueno 2006), como pueden ser manchas, quemaduras, dobleces de las esquinas de las hojas para marcarlas, desgaste y engrase de la esquina inferior derecha (habitual zona para pasar página) o anotaciones en los márgenes a tinta, grafito, lápiz de color, etc. 
Como resultado de este uso nos encontramos frecuentemente con reparaciones que convirtieron el interior de estas obras en una amalgama diversa de cosidos y parches. Las recomposiciones y adaptaciones a la liturgia es uno de los hechos que ha provocado un daño más diverso en estos libros. Esto se refleja en alteraciones en la numeración, en la ley de Gregory (en un cuaderno de pergamino las páginas enfrentadas presentan la misma cara del pergamino, alternándose pelo con pelo y carne con carne sucesivamente y por tanto, dos caras blancas y dos amarillentas). Es frecuente el guillotinado para adaptar el cuerpo del libro a unas nuevas tapas o en el proceso de reencuadernado $\mathrm{y}$, por supuesto, a numerosas alteraciones en el texto y en la música. Las correcciones se llevaban a cabo de distinta manera: raspando, tachando, colocando el nuevo texto al lado o tapando el texto original con parches de papel o pergamino y colocando el nuevo texto encima [Figura 3]. En estas recomposiciones las letras capitales podían ser recicladas, eliminándose parcialmente para transformarlas en otras o aprovechándolas para otros volúmenes.

\section{El desuso}

El desuso no fue un aspecto que favoreciera tampoco a estos volúmenes litúrgicos, ya que el desinterés y su traslado a lugares más apartados de los recintos religiosos hicieron que proliferaran otra serie de daños, si caben más devastadores que los anteriores [Figura 5]. Es bastante usual encontrar gran acumulación de polvo y suciedad siendo campo abonado para insectos bibliófagos como cucarachas, pececillos de plata o piojos del libro. Con la oscuridad como cobijo nos encontramos la devastadora labor realizada por las termitas y los roedores y el almacenaje en buhardillas y áticos con ventanas rotas permite la acción y restos causadas por las palomas y otras aves (y especialmente sus excrementos). Con su abandono también proliferan los hurtos, el recorte de sus bellas iluminaciones o el comercio con anticuarios o coleccionistas que no dudan en venderlos recortados; y lamentablemente ¡hablamos en presente!

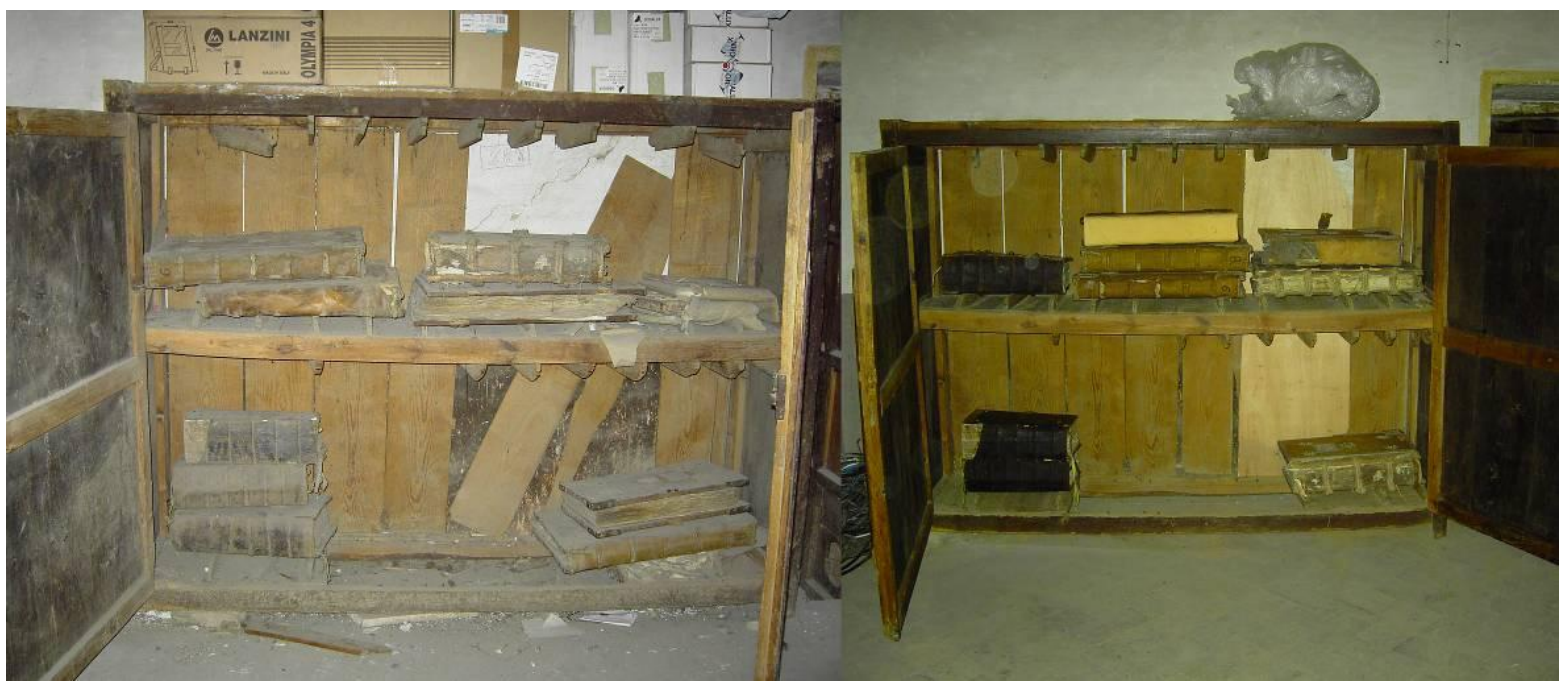

Figura 5. Ejemplo de almacenamiento inadecuado de los libros de coro en una iglesia de Granada y su limpieza y conservación básica realizada recientemente. 


\section{La preservación de cantorales: sistemas de almacenaje}

El concepto de "valor" que ha rodeado estos libros a lo largo de la Historia es un aspecto paradójico, encontrándose eso sí, unido desde un principio al término de preservación. Durante el periodo de empleo habitual sí existía una preocupación por su conservación vinculada a su utilidad en el desarrollo del culto. Así se producían por un lado enmiendas, adobos o reparaciones de las partes deterioradas, adecuaciones del texto y de la música y renovaciones. Por otro lado se fabricaban muebles específicos, se designaba personal para su custodia e incluso se llegaba a sancionar bajo pena de excomunión la desaparición del patrimonio bibliográfico de una comunidad religiosa ${ }^{3}$.

Aunque hoy en día la preservación en general es un término amplio cuya delimitación ha sido motivo sobrado de debate entre profesionales, en el pasado ya se tenía claro uno de sus objetivos principales en referencia a los libros corales, el proporcionar las condiciones óptimas necesarias para asegurar que la información sobreviviese a lo largo del tiempo; claro está sin atender en general a otros principios ahora irrefutables como el respeto a la integridad física o estética del original, la mínima intervención o la diferenciación de lo añadido. Por ello se realizaban elaboradas librerías que preservaban a estas obras de las principales causas exógenas de deterioro [Figura 6], aunque en las fuentes bibliográficas consultadas, las referencias más tempranas encontradas respecto al almacenamiento de libros hacen alusión al uso de arcas 4 . Como caso concreto, podemos citar la catedral de Cuenca, donde hay datos sobre la labor realizada por un carpintero entallador, Juan de Alarcón, que en 1563 realiza un cajón para los libros de coro. Aunque no se especifica cómo sería (Pérez 2007: 149). También hay referencias de armarios específicos para albergar esta tipología libraría, como la siguiente: El armario es un mueble lujoso y exclusivo para contener los preciados códices. Su lugar de emplazamiento es habitualmente el escriptorio, junto al atril y la silla del escribano. Las iglesias disponían también de armarios donde se guardaban los objetos de culto, cartas de donación y libros de coro. (García 1993: 247).

En cuanto a las zonas de almacenaje, independientemente de su diversa ubicación, la nota común entre ellas es su cercanía al coro, para reducir en la medida de lo posible el trasiego diario de estos pesados libros. Por desgracia el lugar de almacenamiento no solía estar formado por librerías o armarios corales ${ }^{5}$ en muchas ocasiones, quedando muchos de estos volúmenes almacenados en capillas contiguas al coro, apilados sobre bancos o algunos de ellos incluso repartidos por el suelo ${ }^{6}$.

Caso excepcional de preservación gracias al buen diseño lo encontramos en la librería coral de la colección del monasterio de Yuso, en San Millán de la Cogolla [Figura 6], en donde la humedad y la ventilación son parámetros controlados en la estructura fabricada ex profeso; bajo los raíles de extracción en la base de la librería se colocó alabastro, material muy higroscópico que absorbe la humedad excesiva y la devuelve en períodos de sequedad y se realizaron decorativos vanos en la pared para crear una libre circulación del aire y evitar la formación de un microclima excesivamente húmedo y el consiguiente ataque fúngico. Otro problema estudiado en esta librería es el control del ataque biológico y para ello se buscó una sencilla solución: en la parte baja de la librería se colocaron "gateras" para que los felinos pudieran acceder y mantuvieran alejados a ratones o insectos de estos preciados libros.

En la librería coral del colegio seminario del Corpus Christi o del Patriarca en Valencia [Figura 7], también se abrieron vanos en la pared, siendo la parte trasera de madera y separada de la pared para evitar humedades. En este segundo ejemplo la librería carece de puertas, que sí fueron colocadas en la de Yuso, al igual que en muchos otros armarios construidos y solían tener llave e incluso en ocasiones, una persona encargada de su custodia, preservándose así los volúmenes del polvo y de los "amigos de lo ajeno" 7 . 


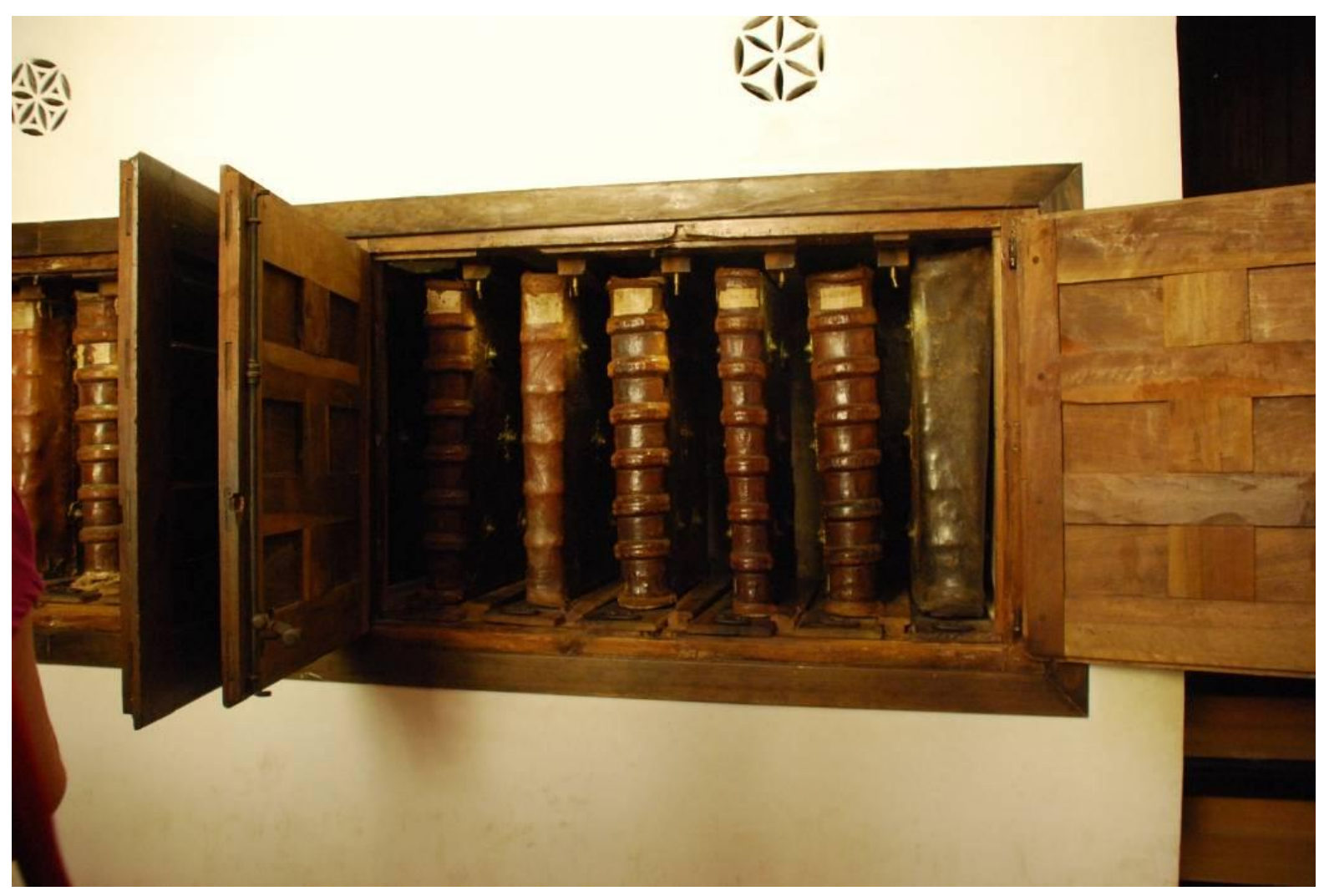

Figura 6. Librería coral del monasterio de Yuso en San Millán de la Cogolla, La Rioja.

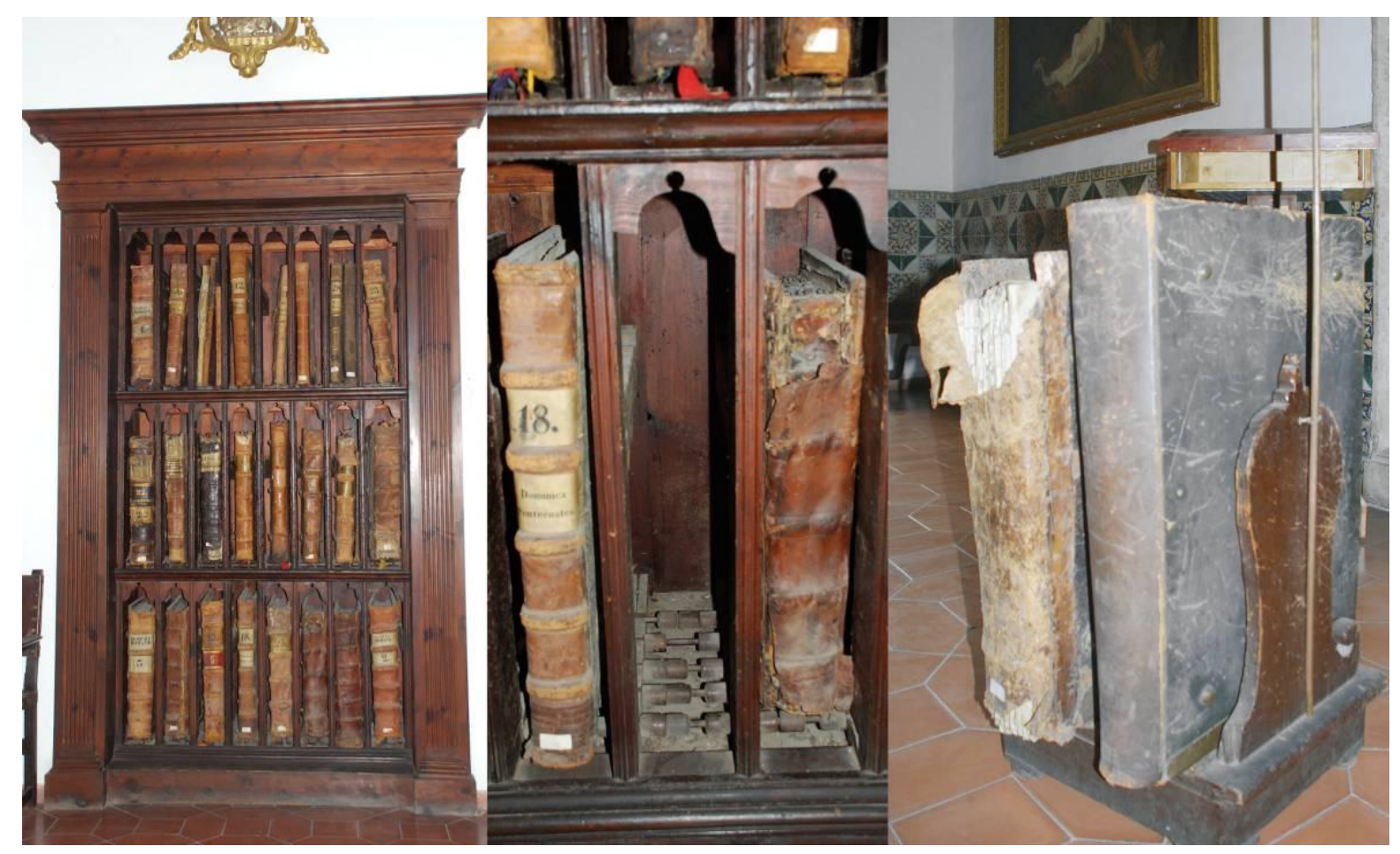

Figura 7. De izquierda a derecha: vista general de la librería, detalle del interior de los casilleros y mueble auxiliar empleado para el transporte de los libros hasta el facistol. Librería coral del colegio seminario del Corpus Christi, Valencia. 
Estas librerías solventaron también el tema de la manipulación; suelen estar divididas en casilleros individuales ${ }^{8}$ para evitar que un volumen apoye sobre otro dificultando su manejo. Además, en el interior de cada casillero de la librería del Corpus Christi de Valencia se colocaron unas ruedas metálicas que facilitaban su extracción, aunque esto no evitaba "tirar" en cierta medida del libro, problema que se solucionó en Yuso con raíles de madera extraíbles colocados en la base de cada cantoral. A veces se colocaban para facilitar su extracción dos pequeñas ruedas en los cantos inferiores de las tapas de los libros, piezas que se han encontrado en los del monasterio de Guadalupe de Cáceres y en los de la catedral de Murcia.

Como se ha visto, los cantorales por su gran formato, deben ser almacenados de forma que se facilite su extracción y en espacios ajustados a su tamaño. Si son colocados en posición horizontal, que parece ser el sistema empleado en las librerías de libros de gran formato o peso (así se puede apreciar por ejemplo en algunas pinturas sobre tabla medievales), no es aconsejable amontonarlos y si es en vertical es necesario que cada casillero sea ocupado por un solo cantoral [Figura 8]. En este sentido destaca el buen acabado de la librería coral de la Capilla Real de Granada, de madera con puertas y malla metálica y baldas independientes con raíles y las superficies forradas de textil.

Las estanterías de madera son desaconsejadas en algunos estudios por su contenido ácido (Mc Cleary y Crespo 2006: 52) y con las metálicas, incluso las abiertas, hay que tener mucho cuidado con las posibles condensaciones de agua por los cambios de temperatura. En cualquier caso, es necesario que carezcan de elementos que puedan producir daños en estos libros y que los tornillos o tuercas utilizados sean de materiales anticorrosivos. Además deben tener un buen acabado químico con pintura anticorrosiva, repelente de insectos e ignífuga. En el caso de ser muebles con puertas, es esencial una buena ventilación que evite la condensación del aire en su interior (Bello y Borrel 2002: 102-103).

Respecto al uso de estanterías metálicas las encontramos preparadas para la colocación vertical de los volúmenes, como en el Sacromonte de Granada o en horizontal, como en la catedral de Pamplona, aunque ninguna de éstas sea ideal.

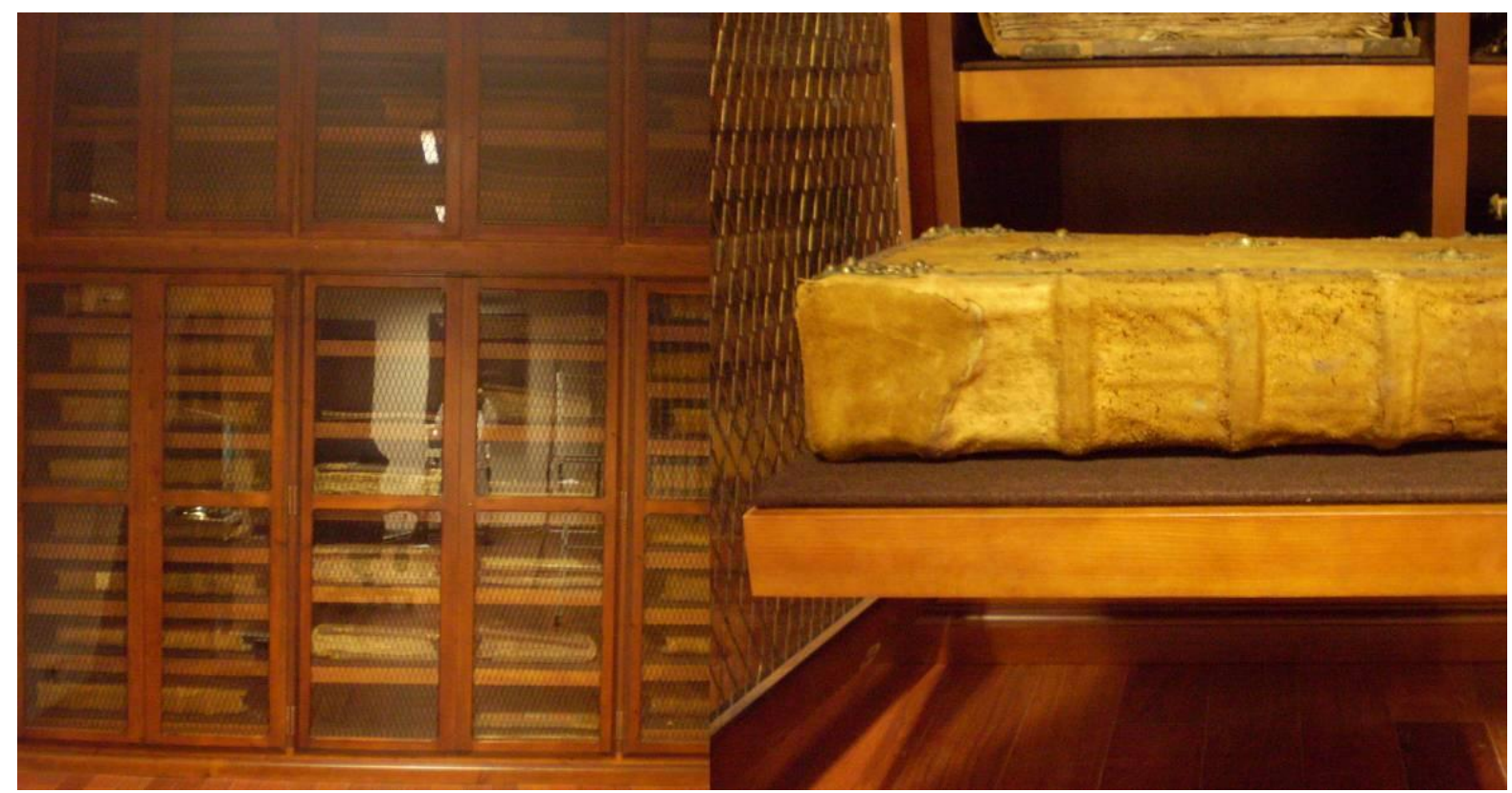

Figura 8. Vista general y detalle de la excelente librería coral de la Capilla Real de Granada; fotografías de Ma Jesús Delqado. 
En el caso de la librería sacromontana [Figura 9], el nuevo sistema ha mejorado el anterior de madera, de muy mala factura y muy deteriorado; el cambio de ubicación ha permitido no obstante conservar el antiguo archivo y estanterías detrás del órgano y trasladar los volúmenes a la nueva zona de archivo general de la institución. Sin embargo el nuevo sistema no está totalmente preparado para evitar el rozamiento de los cortes y cejas del pie de los libros y tampoco soluciona el deterioro y desgastes por el roce de unos elementos decorativos metálicos con otros ya que los casilleros no son individuales (Bueno: 2005), o con los propios rieles de las estanterías (similares en el caso de las del Sacromonte o Pamplona) que tienen unos filos muy cortantes.

En las estanterías metálicas de la catedral de Pamplona [Figura 10] la intención ha sido acertada pero la solución aplicada no del todo. Se han empleado estanterías comerciales adaptadas (dos estanterías estrechas una delante de la otra), que no llegan a cubrir el plano de los libros grandes. Además la falta de espacio ya ha llevado a que se acumulen ejemplares unos sobre otros o que se amontonen otros elementos sobre los libros como cajas, marcos de fotos, etc.

\section{Las nuevas tecnologías al servicio de la conservación de los libros de coro}

Aunque ya no directamente relacionada con las librerías corales, pero sí con la conservación, hay dos aspectos que se tuvieron en consideración en el pasado y que siguen teniendo importancia en la actualidad. Por un lado cabe mencionar la preservación a través de la copia, actualmente solventada con la digitalización de libros y por otro la preservación en relación con la concienciación de los usuarios y responsables de estas obras. Ya a finales del siglo XIX, en colecciones como la de la catedral de Sevilla se aconsejaba el reemplazo de volúmenes originales por impresos para evitar en la medida de lo posible el trasiego diario de estos cantorales (Marchena 1998: 29). Y hoy en día el uso de las nuevas tecnologías ha facilitado la digitalización de los volúmenes y su difusión a nivel mundial. Destacamos el proyecto del Seminario Nacional de Música en la Nueva España y el México Independiente del Instituto de Investigaciones Estéticas de la UNAM, México: "Libros de coro en MUSICAT. Rescate, conservación, catalogación y divulgación de la colección de 121 libros de coro de la catedral metropolitana de la ciudad de México" que se puede ver en http://musicat.unam.mx/nuevo/librosdecoro.html. Presenta en la web la digitalización de gran parte de la información recopilada.

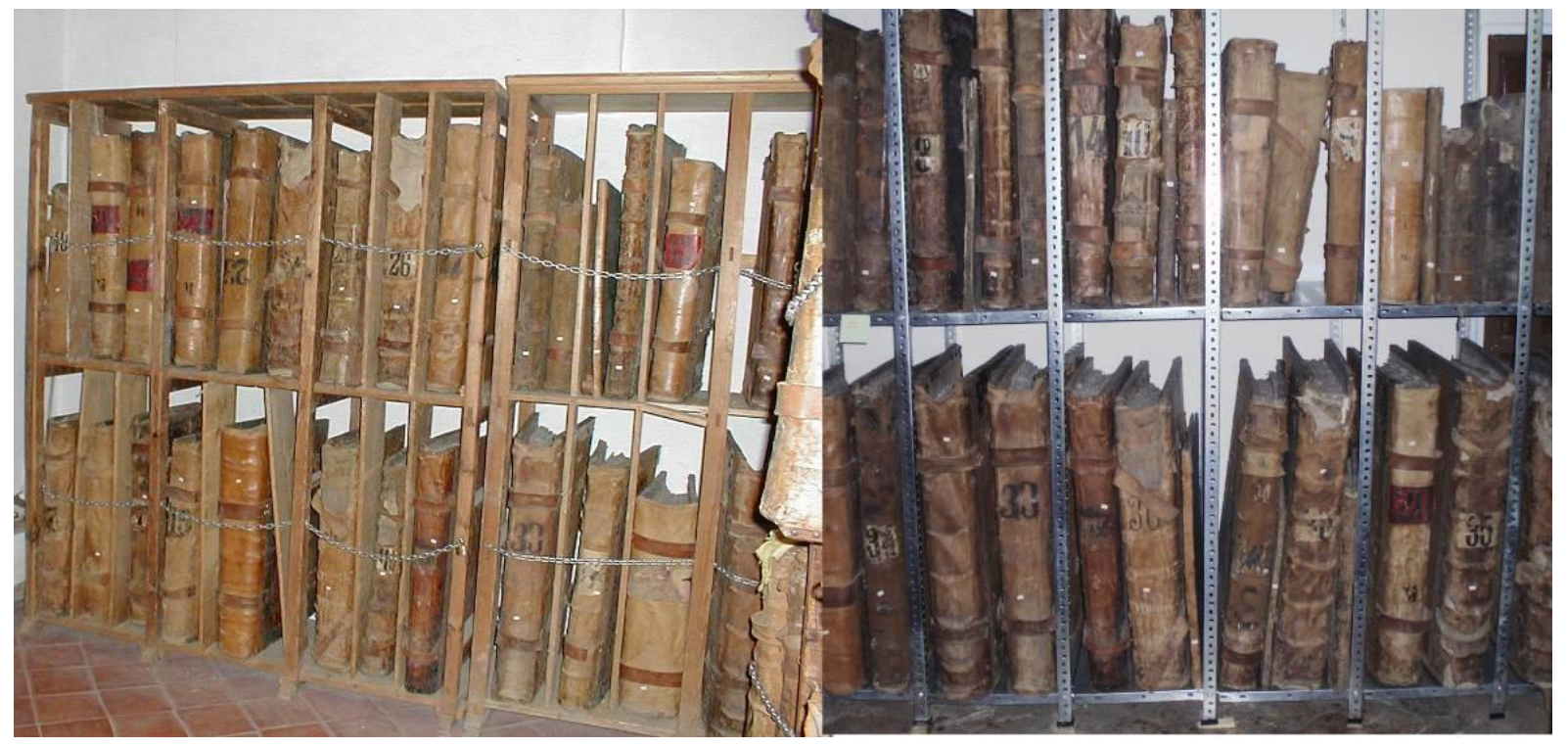

Figura 9. Antigua y nueva estantería de la abadía de Sacromonte en Granada. 


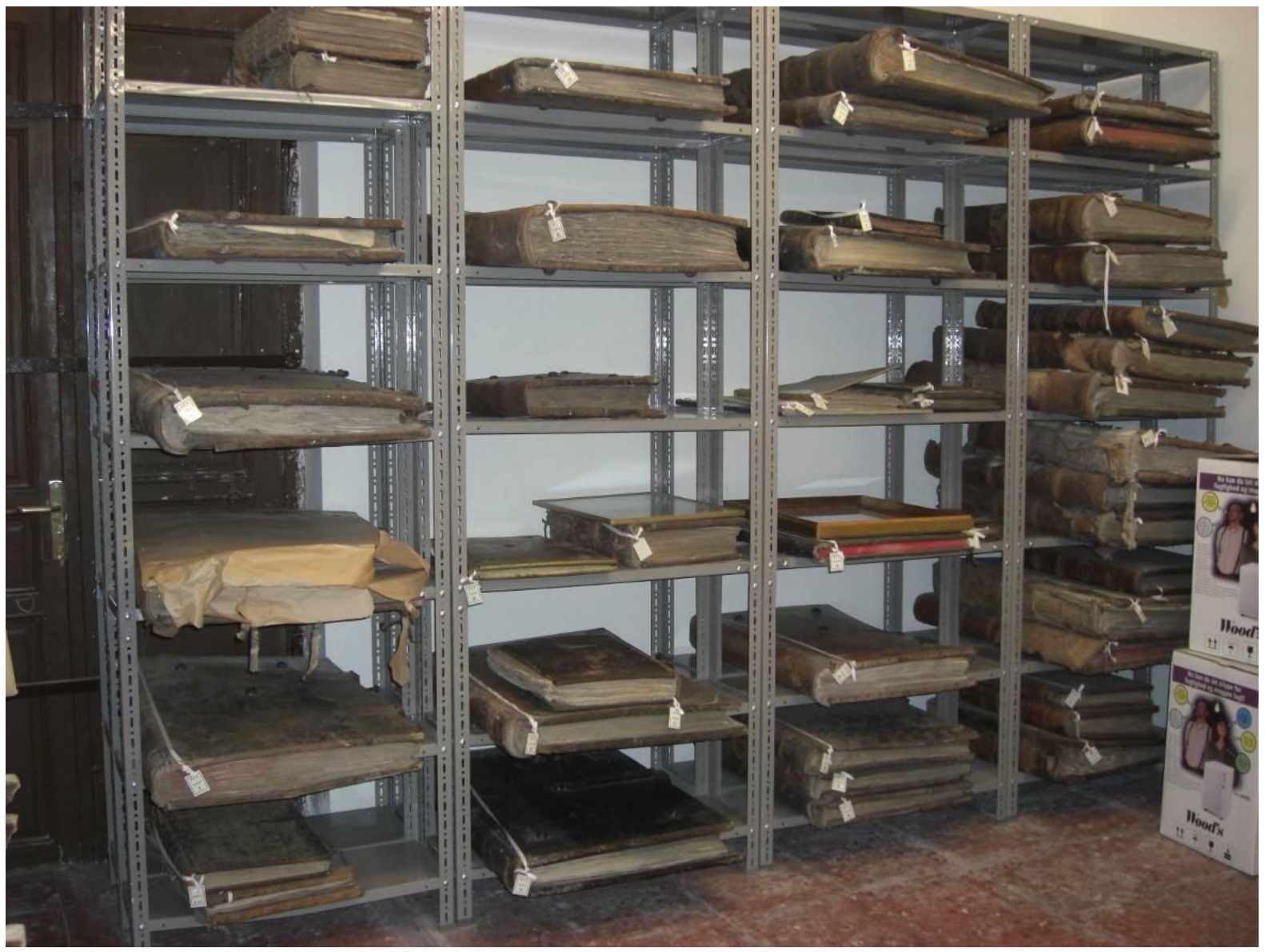

Figura 10. Estantería utilizada en la catedral de Pamplona.

\section{Conclusiones}

La comunicación entre equipos e investigadores individuales en este ámbito, la interacción de diversos profesionales (conservadores-restauradores, musicólogos, historiadores del arte, científicos especializados, etc.) y los responsables, la publicación y difusión de los estudios que se realicen, la actualización de inventarios e investigación histórica, o la catalogación y descripción de materiales, contenidos musicales y estados de conservación, son tareas aún pendientes de realizar y que estamos intentando poner en marcha para contribuir, sin duda, a la requerida puesta en valor de estos bienes culturales. Quisiéramos hacer una llamada de atención especialmente hacia las colecciones ubicadas en pequeñas y medianas instituciones (incluso ahora formadas por unos pocos volúmenes) que no han recibido aún la atención de los investigadores (e incluso a veces de los propios responsables de su custodia), para que se contribuya al menos a su conocimiento y no continúen desapareciendo por su deterioro o puesta a la venta.

Se hace además muy necesario hacer un trabajo reflexivo sobre los criterios de intervención a aplicar en los cantorales, ya que en muchas ocasiones aún hoy se siguen reencuadernando y modificando en su estructura original a pesar de que ya no se tenga la necesidad de que recuperen un aspecto renovado dado que probablemente nunca vuelvan a ser usados como elementos en el culto. ¿No deberíamos empezar a tratar a estos bienes culturales con criterios más arqueológicos 
que restauradores? Evidentemente se deberían hacer importantes labores de conservación de muchos de los volúmenes y especialmente de control y mantenimiento del entorno, incluido en el acceso de las personas, pero creemos se deberían limitar las intervenciones restauradoras indiscriminadas, especialmente las realizadas por encuadernadores sin conocimiento de las especiales características e historia de estos libros.

Para finalizar y aplicable a este patrimonio en particular y a todos los bienes culturales en general, quisiéramos destacar cómo la concienciación sobre la importancia cultural, material e histórica de estos bienes, así como su puesta en valor, suponen un paso primordial para la correcta conservación de los libros corales. Existe el ejemplo de una colección andaluza que sobrevivió a una guerra civil gracias a una medida de emergencia: Cuando más se deterioraron fue en tiempo de la guerra civil española, pues no sabemos quién, pero desde luego alguien que conocía bien el valor de aquellos libros y que temía que pudieran perderse o destruirse, se le ocurrió la idea de guardarlos en las bóvedas del templo (texto anónimo disponible en la web bajo el título Libros corales, consultar bibliografía). Se deterioraron, aunque algunos de ellos sobrevivieron lamentablemente: hemos encontrado en su colección varios ejemplares restaurados hace unos años en los que se ha empleado un revestimiento de guaflex@ (un soporte celulósico impregnado con resinas y pintado acrílico de la marca Guarro Casas S.A. que intenta imitar a la piel), de color naranja y con guardas de papeles de agua y cartulinas azules, acabados y materiales jamás empleadas en estos volúmenes. Intervención realizada con buena voluntad pero que creemos ha descontextualizado y deteriorado irreversiblemente el libro manuscrito en pergamino del siglo XVII, devolviéndole un aspecto ficticio y artificial.

Definitivamente si no tomamos medidas urgentes y se establecen unos criterios básicos o recomendaciones de intervención, es probable que la progresiva pérdida o alteración de este patrimonio nos lleve a una situación irreversible en muchos casos.

\section{Notas}

[1] Suárez González menciona el uso de varios facistoles en el recinto del coro de la residencia de canónicos regulares de San Isidoro de León: un facistol pequeño sobre el que se depositaba el breviario que servía como guía durante la liturgia y uno grande, redondo con tres lazenas en el pie. Éste último tenía zona de almacenaje en la parte inferior. (Suárez 2005).

[2] En el colegio seminario del Corpus Christi (Valencia) el facistol tiene un pie en la parte baja por lo que se recurría al uso de un pequeño mueble auxiliar para almacenar dos o tres libros en posición vertical.

[3] Estos datos pueden ser consultados en red en la publicación de Suárez González. (Suarez 2005).

[4] García Cuadrado en el estudio de las cantigas del Códice de Florencia hace una descripción y estudio de las iluminaciones, con información sobre el mobiliario utilizado en el reino alfonsí (García 1993).

[5] Por ejemplo según García Luján, de los libros empleados en el servicio del coro de la catedral de Cádiz, unos estaban siempre dentro del coro y otros se llevaban al mismo según las necesidades litúrgicas, siendo guardados en armarios-librerías. En el Libro de Cabildos de la abadía del Sacromonte de Granada no 6, p. 275v de 16 de junio de 1707 leemos: Propúsosse por el Señor Abad (...) hazer un oratorio y librería para el servicio del coro.

[6] Así se comenta que pasaba en la catedral de Sevilla, donde según Ceán Bermúdez (1800-1804) algunos de ellos: se veían amontonados en el suelo (del coro) quitando la vista y lucimiento y aún perjudicando al excelente pie del facistol. (Marchena 1998: 29). 
[7] En la obra de Pérez Berná se habla de un armario con llave que encarga el cabildo y de otro que se reserva en el anteaula, controlado por el sochantre, para los libros de coro (Pérez 2007: 190).

[8] Aunque actualmente la colección de libros de coro de la catedral de Sevilla se encuentra en estantes metálicos, no siempre ha sido así, en 1507 el cabildo acuerda que se haga una librería de madera donde cada libro ocupaba un compartimento, para facilitar su extracción (Marchena 1998: 28).

\section{Referencias bibliográfica}

"Libros corales", en Música litúrgica.

(http://www.musicaliturgica.com/assets/plugindata/poolb/Libros\%20Corales.pdf) [consulta 20/2/2011].

BELLO URGELLÉS, C. y BORRELL CREHUET, A. (2002). El patrimonio bibliográfico y documental. Claves para su conservación preventiva. Gijón: Trea.

BIURRUN SOTIL, T. (1935). "La Sillería del Coro de la catedral de Pamplona. Impropiamente atribuida a un imaginario Miguel de Ancheta", Boletín de la Comisión de Monumentos Históricos y Artísticos de Navarra, Sección 3a- ARTE: 285-307. (http://www.euskomedia.org/PDFAnlt/cmn/1935286307.pdf) [consulta: 22/2/2011].

BLAZEJ V. (1984): Technology of leather and furs. Praga: SNTL-ALFA.

BUENO VARGAS, J. (2005). "Los libros de coro y las particularidades de su encuadernación: las cubiertas de los cantorales de la abadía del Sacromonte de Granada", PH, Boletín del Instituto Andaluz del Patrimonio Histórico, 53: 44-57.

BUENO VARGAS, J. (2006). "Deterioro en encuadernaciones manuscritas de gran formato: causas intrínsecas de alteración en los libros de coro", Cuadernos de Restauración, 6: 43-56.

BUENO VARGAS, J. ESPEJO ARIAS, T., PÉREZ RODRÍGUEZ, J. L. Y JUSTO ERBEZ, A. (2006): "Colour in the Seventeenth-Century Miniatures of Spanish Choir Books", Restaurator: International Journal for the Preservation of Library and Archival Material, vol. 27, nº 3: 143-161.

BUENO VARGAS, J., ESPEJO ÁRIAS, T., LÓPEZ MONTES, A. (2005). "Colour as an indication of the Start of a new chapter. Capital letters in illuminated codices". En 10 th Congress of the International Colour Association- AIC Colour 05. Granada. (http://www.cienciayculturaescrita.es/esp/images/stories/descargas/2005-AIC-Granadacolouras.pdf) [Consulta 1/9/2011].

ERHARDT D. y MECKLENBURG M. (1994). "Relative Humidity re-examined". En Preventive Conservation, practice, theory and research. Ottawa: IIC Preprints of the Contributions to the Ottawa Congress, 32-38.

FERNÁNDEZ-SHAW TODA, M. F. (1994). "Sotocoros y frentes de madera en la provincia de Ávila", Anales de historia del arte, 4: 385-392. (http://revistas.ucm.es/ghi/02146452/articulos/ANHA9394110385A.PDF) [ consulta 20/2/2011].

GARCíA CUADRADO, A. (1993). Las cantigas del códice de Florencia. Murcia: Secretariado de Publicaciones de la Universidad de Murcia.

GARCÍA LUJÁN, J. A. (2005). "Los libros corales de la catedral de Cádiz", en Dialnet: Historia, instituciones, documentos, 32: 145-174. (http://dialnet.unirioja.es/servlet/articulo?codigo=2903847) [consulta: 22/1/2001].

GÓMEZ, Ma. L. (2002). La restauración. Examen científico aplicado a la conservación de obras de arte. Madrid: Cuadernos Arte Cátedra.

Granada, Archivo del monasterio del Sacromonte, Libro de Cabildos, ms. no 11, f. 325v. 
Granada, Archivo del monasterio del Sacromonte, Libro de Cabildos, ms. n 5, f. 267r.

Granada, Archivo del monasterio del Sacromonte, Libro de Cabildos, ms. no 6 f.114r.

JIMENO, A. (1996). Biología, Madrid: Santillana.

MARCHENA HIDALGO, R. (1998). Las miniaturas de los libros de coro de la catedral de Sevilla: el siglo XVI. Sevilla: Universidad de Sevilla, Fundación Focus- Abengoa.

MARTín PRADAS, A. (2004). Sillerías de coro de Sevilla. Análisis y evolución. Sevilla: Guadalquivir Ediciones y Consejería de Cultura de la Junta de Andalucía.

MARTíNEZ BLANES J.M., BUENO VARGAS, J. y PÉREZ RODRÍGUEZ, J.L. (2001). “Estudio científico de los libros de coro de la abadía del Sacromonte de Granada". En III Congreso Nacional de Arqueometría. Sevilla: Universidad de Sevilla, Secretariado de Publicaciones y Fundación El Monte, 145-155.

MC CLEARY J. y CRESPO L. (2006). El cuidado de libros y documentos. Madrid: Clan.

PÉREZ BERNÁ, J. (2007). La capilla de Música de la catedral de Orihuela: las composiciones en romance de Mathias Navarro (ca. 1666-1727). Santiago de Compostela: Universidad de Santiago de Compostela. Departamento de Historia del Arte, área de Música.

QUINTERO ATAURI, P. (1928). Sillerías de coro en las Iglesias Españolas. Cádiz: Real Academia Hispano- Americana de Ciencias y Artes.

RAPHAEL, T. (1993) "Preventive Conservation Recommendations for Organic Objects", Conserve O Gram, 1/3, Washington: DC: National Park Service.

ROSENDO ROIG, S.J. (2007). Los cartujos: diálogos en Miraflores. Burgos: Cartuja de Santa María de Miraflores.

SILVIO GOREM, M. (1997): Auxilios previos para colecciones artísticas e históricas- Cuaderno Técnico n¹, Argentina: edita el autor.

STOLOW, N. (1987). Conservation and exhibitions. Packing, transport, storage and environmental considerations, London: Butterworths.

SUÁREZ GONZÁLEZ, A. (2005). “El patrimonio bibliográfico comunitario de Santa María de la Vega (Salamanca) en 1577", en Dialnet. Estudios humanísticos. Filología, 27: 209-232.

(http://dialnet.unirioja.es/servlet/articulo?codigo=1271440) [22/01/2011].

UNESCO (1979): "La conservación de los bienes culturales", En Museos y Monumentos XI. (http://unesdoc.unesco.org/images/0013/001355/135545so.pdf) [26/02/2011].

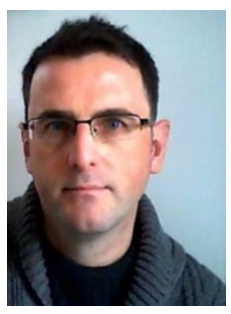

Javier Bueno Vargas

Profesor contratado doctor. Facultad de Bellas Artes. Universidad de Sevilla C/Laraña 3.41003 Sevilla (Spain)

javierbueno@us.es

Doctor en Bellas Artes y Ldo. en Geografía e Historia, U. Granada. Comenzó su estudio de los cantorales españoles con la tesis: los libros de coro en pergamino ilustrados de la abadía del Sacromonte de Granada: estudio histórico medioambiental, de materiales y técnicas (2002). 


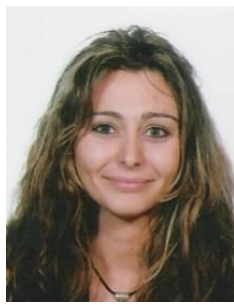

\section{Elena Vázquez Jiménez}

Facultad de Bellas Artes de Sevilla.

H_vazquez@hotmail.es

Lda. en Bellas Artes en Sevilla, Especialidad de Conservación y Restauración. En 2010 presentó su trabajo de investigación Caracterización y evaluación de causas de alteración y daños en libros de coro mediante un sistema gestor de bases de datos. Actualmente se encuentra redactando su tesis doctoral.

Artículo recibido el 13/03/2011

Artículo aceptado el 31/03/2012 